\title{
The Investigation of Levels of Empathy in Nurse Candidates
}

Nurcan ERTUĞ

Ufuk University, School of Nursing, Ankara, Turkey

\section{ABSTRACT}

Objective: The aim of this study was to determine the empathy levels in students studying innursing department of a university. Methods: This descriptive study was conducted in a university with 168 students studying nursing in a university in Ankara. The data were collected by "Jefferson scale of empathy for nursing students." The higher scores indicate a higher empathy level. The data were analyzed using mean, standard deviation t-test, and One-way ANOVA.

Results: Participants' mean age was $21.21 \pm 1.958$ and $86.3 \%$ of them were females. The students' mean score on the scale was $90.04 \pm 13.796$. The average total score of female students were higher than the male students $(t=2.389, p=0.018)$. Students with higher grade point average were found to have higher empathy score $(\mathrm{F}=5.221, \mathrm{p}=0.006)$. The score on the scale of students who had previous nursing qualification was higher than that of the others $(\mathrm{t}=-2.335, \mathrm{p}=0.021)$. It was found that the age $(\mathrm{r}=-0.020$, $\mathrm{p}=0.792)$, willingness to work as a nurse after graduating $(\mathrm{t}=-0.311, \mathrm{p}=0.756)$, academic year $(\mathrm{F}=2.306, \mathrm{p}=0.079)$, or hospitalization experiment $(\mathrm{t}=-1.118$, $\mathrm{p}=0.265)$ of the students did not influence the empathy.

Conclusion: The study showed that the level of empathy in the nursing students is at a medium level. It was determined that the empathy level was influenced by academic success, gender, and previous nursing qualification. Additionally, empathy level was not influenced by the academic year, hospitalization experiment, or willingness to work as a nurse after graduating. Performing a change in the upward empathy while updating curriculum or planning nursing education can be considered.

Keywords: Empathy, nursing students, nursing education

\section{Introduction}

Despite various definitions, empathy in the general sense mostly refers to instinctively understanding how others feel and think. Empathy can be expressed in terms of showing basic emotions such as joy, sadness, and anxiety (1). Nurses can be affected negatively by having to face people who suffer every day and may develop emotional fatigue. However, it is known that empathic behavior contributes to the improvement of patient care outcomes while the job satisfaction of healthcare staff increases (2). In addition, empathy reduces malpractice and increases patient satisfaction with patient participation and compliance (3).

Empathy is necessary in all situations where therapeutic communication is required (2). Therefore, it is expected that nurses, who are health professionals, should be empathic. Studies on the empathy level of nursing students abroad using the Jefferson empathy scale show that the averages are not high $(4,5)$. When the literature was examined, no study was found that determined the empathy level of nursing candidates in our country using the scale prepared for nursing students. It is expected that the results of the present study will be effective in the plans or curriculum updates of teaching academic staff of nursing education institutions. In this context, the aim of the present study was to determine the empathy levels of students studying at nursing schools.

Cite this article as: Ertuğ N. The Investigation of Levels of Empathy in Nurse Candidates. Bezmialem Science 2018; 6: 37-42. 


\section{Methods}

Descriptive research was conducted during the spring semester of the 2015-2016 academic year on students who were studying in a nursing department of a university in Ankara. Of 237 students who were studying in the nursing department, only 168 agreed to participate in the study (response rate: $70.8 \%$ ). To conduct the study, approval from the ethics committee of the university and permission from the institution and the students were obtained.

\section{Data collection form}

The data collection form comprised two parts. In the first part, there were questions about whether the students were willing to work as a nurse after graduation as well as their age, gender, grade point average (GPA), grade level, and previous hospitalization status. In the second part, the "Jefferson Scale of Empathy for Nursing Students (JSENS)" was available. The Jefferson empathy scale was developed by Hojat et al. (6) to determine the empathy levels of physicians and was adapted to Turkish conditions in 2012 (7). In 2009, the scale was adapted for nursing students by Ward et al. (8). A Turkish validity-reliability study of the adapted scale was performed by Yanik and Saygili (9). The original JSENS comprises 20 items and 3 factors; however, the Turkish form comprises 18 items. Reportedly, the $5^{\text {th }}$ and $18^{\text {th }}$ items in the Turkish scale were removed by the researchers because the factor load was determined as low (9). To use JSENS in the study, permission was obtained from the writers who adapted the scale to Turkish settings. Like the original version, the 18-item Turkish form of JSENS also comprises 3 factors: perspective taking ( 9 items), compassionate care (7 items), and standing in the patients' shoes (2 items). JSENS is similar to a 7-point Likert scale, and the points that can be obtained in the Turkish form vary between 18 and 126. The higher the score, the higher is the level of empathy. The data collection form was distributed to the students collectively either during recess or when all the classes ended, and the forms were collected immediately after they were filled out.

\section{Statistical analysis}

The collected data was coded and analyzed using Statistical Package for the Social Sciences, version 21.0 (IBM Corp., Armonk, NY, USA). For descriptive statistics, mean and standard deviation were used to determine empathy scores. The t-test and one-way ANOVA analysis were used to determine the effects of independent variables on empathy. Statistical significance level was determined as $\mathrm{p}<0.05$. The Cronbach alpha coefficient of the present study was found to be 0.798 . Accordingly, the scale was considered highly reliable for this research sample.

\section{Findings}

The present study included 160 students with an average age of $21.21 \pm 1.958$ years; $86.3 \%$ of them were female. Most of graduation, $61.9 \%$ had an average general GPA, and $15.5 \%$ had had high school nursing education.

As shown in Table 1, the average score of the participants from JSENS was $90.04 \pm 13.796$. The average scores of the participants according to the subscales of the scale are presented in the same table. The highest average scale point in the subscales was found in the $2^{\text {nd }}$ factor, "compassionate care" ( $\bar{X}=50.44 \pm 7.877)$, whereas the lowest average scale point was found in the "standing in the patients' shoes" factor (X $=7.30 \pm 2.855)$.

The total average score obtained from JSENS according to the independent variables are presented in Table 2. The total average score of the scale and the subscale of "standing in the patients' shoes" scores of the female students was found to be higher than that of the male students $(t=2.389, \mathrm{p}=0.018)$.

The GPA of the students was categorized as low (0-1.99), medium (2.00-2.99), and high 3.00-4.00 (Table 2). A statistically significant difference was found between the GPA of students and their total score of JSENS ( $\mathrm{F}=5.221, \mathrm{p}=0.006$ ). At the same time, a low level of positive correlation was observed between GPA and both the average score of JSENS and the average scores of all factors $(r=0.229, p=0.004 ; r=0.157$, $\mathrm{p}=0.050$; and $\mathrm{r}=0.181, \mathrm{p}=0.023$, respectively). According to this, as the average of the students' GPA increases, the average score of JSENS also increases.

The average score of JSENS of the students who had received nursing education in high school was higher than that of the other high school graduates $(\mathrm{t}=-2.335, \mathrm{p}=0.021)$ (Table 2).

There was no statistically significant difference between the average score of JSENS of the participants and their being disposed to work as a nurse after graduation $(t=-0.311, \mathrm{p}=0.756)$ and their previous hospitalization experience $(\mathrm{t}=-1.118$, $\mathrm{p}=0.265$ ). No difference was found between the average score of JSENS and the class levels $(\mathrm{F}=2.306, \mathrm{p}=0.079)$. There was no correlation between the age of the students and their total average score of JSENS $(\mathrm{r}=-0.020, \mathrm{p}=0.792)$.

The average scores of JSENS of the participants are shown in Table 3. The highest score was observed in the $2^{\text {nd }}$ item (the patients feel better when the nurses understand how the patients feel), "perspective taking," with a score of 6.04. The lowest score (3.33) was observed in the $6^{\text {th }}$ item, "standing in

\section{Table 1. Score averages according to factors}

\begin{tabular}{|l|c|c|}
\hline Factors of the scale & $\overline{\mathrm{X}}$ & SD \\
\hline Perspective Taking & 32.30 & 8.968 \\
\hline Compassionate Care & 50.44 & 7.877 \\
\hline Standing/Walking in the Patients' Shoes & 7.30 & 2.855 \\
\hline Total & 90.04 & 13.796 \\
\hline
\end{tabular}

SD: standard deviation 


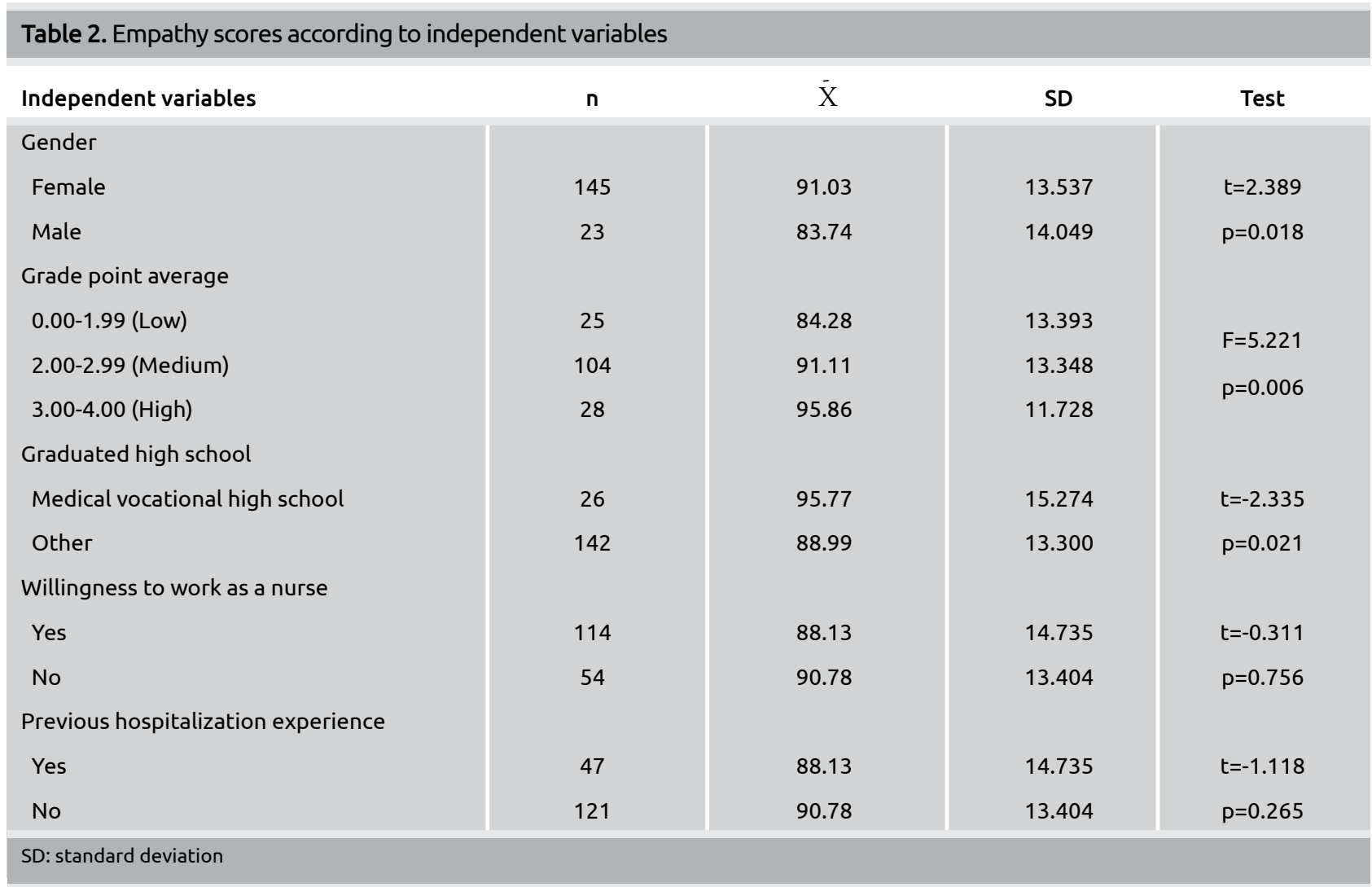

the patients' shoes" (because people are different from each other, it is hard to see events from the perspective of the patients).

\section{Discussion}

In the present study examining the empathy levels of nursing students, the average score of JSENS of the participants was found to be moderate, with $90.04 \pm 13.796$ points. This average is significantly lower than that observed in other studies conducted abroad using the Jefferson empathy scale containing 20 items $(4,10,11)$. However, if we consider that the total number of items in the Turkish version of JSENS used in our study is 18 instead of 20 and the maximum score that can be obtained from the scale is 126 instead of 140 , it may not be appropriate to compare the scores of the present study with those of other studies. However, in a study conducted in Greece using the 20-item JSENS, the average score of nursing students was found to be 88.6, which is lower than the average found in the study we conducted on 18 items (90.04) (5). It is possible to say that the empathy levels of the students in our study are higher than those of the nursing students in the Greek sample.

Similar to the studies that have been performed using the same tool (Jefferson empathy scale), the empathy score averages of the female students in our study sample were higher than those of the male students (10-13). There is no theory in the literature that fully explains the effect of gender on empathy. However, the effect of gender on empathy may be due to the emotional nature of women or the socio-cultural charac- teristics of the countries in which the studies were performed. In contrast, there are studies showing that the level of empathy does not differ based on gender $(4,14)$.

In our study, in addition to a low positive correlation, there was a significant difference between the GPA levels of the students and the average scores of JSENS. As the average score of the students increased, the GPA of the students increased. This result is similar to that of Hamed et al. (15). In contrast, in the studies of Sukhee (16) and Hasan et al (17), it was reported that there is no relationship between the GPA of students and empathy level.

The average score of JSENS of the students who had high school nursing education was higher than that of the other high school graduates $(\mathrm{t}=-2.335, \mathrm{p}=0.021)$. In the literature, there is no study examining the relationship of empathy with previous vocational education. Williams et al. (18) stated that some students in their study might have had previous vocational training and this might have affected their empathy levels. However, because such vocational education was not questioned in the study, no such deduction could be made. Among our participants, the fact that the medical vocational high school graduates had a higher average score of JSENS than other high school graduates suggests that their previous vocational education increased their empathy level.

In a study conducted by Ouzouni and Nakakis (5), it was determined that the level of empathy of the students who wanted to work as a nurse after graduation was higher than that of those who did not want to work as a nurse. In our 
Table 3. Average points of items related to the empathy of participants

\begin{tabular}{|c|c|c|c|}
\hline Items & Factor & $\bar{X}$ & SD \\
\hline 2. Patients feel better when their nurses understand their feelings. & Perspective taking & 6.04 & 1.183 \\
\hline $\begin{array}{l}\text { 4. Understanding body language is as important as verbal communication in } \\
\text { nurse-patient relationships. }\end{array}$ & Perspective taking & 5.98 & 1.183 \\
\hline 20. I believe that empathy is an important therapeutic in its own right. & Perspective taking & 5.97 & 1.320 \\
\hline $\begin{array}{l}\text { 10. Patients value a nurse's understanding of their feelings, which is } \\
\text { therapeutic in its own right. }\end{array}$ & Perspective taking & 5.64 & 1.269 \\
\hline $\begin{array}{l}\text { 16. Nurses' understanding of the emotional status of their patients, as well as } \\
\text { that of their families is one important component of the nurse-patient relationsl }\end{array}$ & $\begin{array}{l}\text { Perspective taking } \\
\text { ip. }\end{array}$ & 5.59 & 1.333 \\
\hline 17. Nurses should try to think like their patients in order to render better care. & Perspective taking & 5.46 & 1.344 \\
\hline $\begin{array}{l}\text { 9. Nurses should try to stand in their patients' shoes when providing care } \\
\text { for them. }\end{array}$ & Perspective taking & 5.35 & 1.414 \\
\hline 15. Empathy is a therapeutic skill without which the nurse's success is limited. & Perspective taking & 5.21 & 1.579 \\
\hline $\begin{array}{l}\text { 13. Nurses should try to understand what is going onin their patients' minds } \\
\text { by paying attention to their nonverbal cues and body language. }\end{array}$ & Perspective taking & 5.20 & 1.398 \\
\hline $\begin{array}{l}\text { 11. Patients' illnesses can be cured onlyby medical or surgical treatment; } \\
\text { therefore,nurses' emotional ties with their patients do not have asignificant } \\
\text { influence in medical or surgical treatment. }\end{array}$ & Compassionate care & 5.11 & 1.842 \\
\hline 19. I do not enjoy reading non-medical literature or the arts. & Compassionate care & 4.92 & 1.994 \\
\hline 14. I believe that emotion has no place in the treatment of medical illness. & Compassionate care & 4.85 & 1.953 \\
\hline 7. Attention to patients' emotions is not important in history taking. & Compassionate care & 4.79 & 1.861 \\
\hline $\begin{array}{l}\text { 1. Nurses' understanding of their patients' feelings and the feelingsof their } \\
\text { patients' families does not influence medical or surgical treatment. }\end{array}$ & Compassionate care & 4.24 & 2.010 \\
\hline $\begin{array}{l}\text { 8. Attentiveness to patients' personal experiences does not influence } \\
\text { treatment outcomes. }\end{array}$ & Compassionate care & 4.23 & 1.788 \\
\hline $\begin{array}{l}\text { 12. Asking patients about what is happening in their personal lives is not helpful } \\
\text { in understanding their physical complaints. }\end{array}$ & Compassionate care & 4.15 & 1.795 \\
\hline 3. It is difficult for a nurse to view things from patients' perspectives. & $\begin{array}{l}\text { Standing/Walking in the } \\
\text { Patients' Shoes }\end{array}$ & 3.97 & 1.739 \\
\hline $\begin{array}{l}\text { 6. Because people are different, it is difficult to see things from patients' } \\
\text { perspectives }\end{array}$ & $\begin{array}{l}\text { Standing/Walking in the } \\
\text { Patients' Shoes }\end{array}$ & 3.33 & 1.615 \\
\hline
\end{tabular}

study, this evaluation was also performed, and no difference was found between the score of JSENS of the students who wanted to work as a nurse after graduation and that of those who did not want to work as a nurse. In our study, there was no statistically significant difference between the average score of JSENS of the participants and previous hospitalization experience. In contrast, Gayef et al. (19) showed that having previously been hospitalized increased the level of empathy among the students. In light of these results, it can be stated that the students who had previous vocational education and hospitalization background have some kind of experience, and this background is reflected in their professional life.

There was no correlation between the age of the students and their total average score of JSENS. In other studies, it has also been reported that age does not have an impact on empathy
$(4,10,18,20-23)$. In this context, the present study is compatible with the literature.

There was no difference between the average score of JSENS and class levels of our participants. Similar results were found in the literature review $(4,11,18,20)$. In contrast, there are also some studies in the literature that report differences between empathy and class level. However, in some of these studies, the level of empathy increased $(5,12,21,22)$, whereas in some, the level decreased $(13,24,25)$.

When the participants' empathy item score averages were examined, it was found that the highest score (6.04) belonged to the $2^{\text {nd }}$ item, perspective taking. Park et al. (25), Paro et al (26), and Rahimi-Madiseh et al. (27) also reported this item as having the highest score in their studies. In addition, item 6 , which had the lowest empathy point average in our study, 
was also found to be the lowest in other studies $(25,26,28)$. Therefore, from this point of view, it can be said that our study is compatible with the literature.

\section{Study limitations}

This study is important because it is the first study using nursing students as participants, using a scale (JSENS) prepared for "nursing students." However, the study has some limitations. First, we cannot generalize because our study was performed with nursing students from only one university and therefore covers a small sample. More sample studies can be planned in our country. The second limitation is that similar to other studies, the data were collected based on the self-report of the students. In this way, students' thoughts might have been revealed, and it is difficult to determine their attitude in this way. Therefore, observational or interventional studies that determine empathic behavior can be suggested. Another limitation is that this study was not longitudinal but cross-sectional. To obtain more detailed data from the participants, longitudinal studies might be conducted in the future.

\section{Conclusion}

As a result of our study, it was observed that the empathy level of nursing students was moderate. It was determined that empathy is affected by academic success, gender, and having high school nursing education, but it is not affected by class level, previous hospitalization experience, and willingness to work as a nurse. Accordingly, teaching staff working in institutions providing nursing education might be recommended to pay more attention to increasing their students' empathy level. In addition to this, a change regarding enhancing the empathy level can be taken into consideration while training plans or curriculum updates are being made.

Ethics Committee Approval: Ethics committee approval was received for this study from the ethics committee of Turgut Özal University.

Informed Consent: Informed consent was obtained from all participants in this study.

Peer-review: Externally peer-reviewed.

Conflict of Interest: No conflict of interest was declared by the author.

Financial Disclosure: The author declared that this study has received no financial support.

\section{References}

1. Peterson P, Baker E, McGaw B. International Encyclopedia of Education. 3rd ed. Oxford: Elsevier; 2010.

2. Stephany K. Cultivating Empathy: Inspiring Health Professionals to Communicate More Effectively. Sharjah: Bentham Science Publishers; 2014.

3. Hojat M. Empathy in Patient Care. New-York: Springer; 2010.
4. McKenna L, Boyle M, Brown T, Williams B, Molloy A, Lewis $\mathrm{B}$, et al. Levels of empathy in undergraduate nursing students. Int J Nurs Pract 2012; 18: 246-51. [CrossRef]

5. Ouzouni C, Nakakis K. An exploratory study of student nurses' empathy. HSJ 2012; 6: 534-52.

6. Hojat M, Mangione S, Nasca TJ, Cohen MJM, Gonnella JS, Erdmann JB, et al. The Jefferson Scale of Physician Empathy: Development and Preliminary Psychometric Data. Educ Psychol Meas 2001; 61: 349-65. [CrossRef]

7. Gönüllü İ, Öztuna D. Turkish adaptation of the student version of the Jefferson Scale of Physician Empathy. Marmara Med J 2012; 25: 87-92.

8. Ward J, Schaal M, Sullivan J, Bowen ME, Erdmann JB, Hojat M. Reliability and validity of the Jefferson Scale of Empathy in undergraduate nursing students. J Nurs Meas 2009; 17: 73-88. [CrossRef]

9. Yanik A, Saygili S. Validity and Reliability of the Turkish Version of Jefferson Scale of Empathy for Nursing Students. Turkiye Klinikleri J Med Sci 2014; 34: 111-9. [CrossRef]

10. Petrucci C, Cerra CL, Aloisio F, Montanari P, Lancia L. Empathy in health professional students: A comparative cross-sectional study. Nurs Educ Today 2016; 41: 1-5. [CrossRef]

11. Brown T, Boyle M, Williams B, Molloy A, Palermo C, McKenna $\mathrm{L}$, et al. Predictors of empathy in health science students. J Allied Health. 2011; 40: 143-9.

12. Magalhães E, Salgueira AP, Costa P, Costa MJ. Empathy in senior year and first year medical students: a cross-sectional study. BMC Med Educ 2011; 11: 1-7. [CrossRef]

13. Raof AM, Yassin BA. Measuring empathy levels among Kurdish medical students in Erbil City, Iraq: Cross-sectional study. Sultan Qaboos Univ Med J 2016; 16: e62-7. [CrossRef]

14. Yücel H, Acar G. Levels of empathy among undergraduate physiotherapy students: A cross-sectional study at two universities in Istanbul. Pak J Med Sci 2016; 32: 85-90.

15. Hamed OAE, Alahwal AMS, Basri AH, Bukhari BM. Personal, Cultural and Academic Factors Affecting Empathy Score in Third Year Medical Students. Int J Educ Res 2015; 3: 727-40.

16. Sukhee A. Empathy in nursing education. 24th International Nursing Research Congress. Prague 2013.

17. Hasan S, Al-Sharqawi N, Dashti F, AbdulAziz M, Abdullah A, Shukkur M, et al. Level of Empathy among Medical Students in Kuwait University, Kuwait. Med Princ Pract 2013; 22: 3859. [CrossRef]

18. Williams B, Boyle M, Earl T. Measurement of empathy levels in undergraduate paramedic students. Prehosp Disaster Med 2013; 28: 145-9. [CrossRef]

19. Gayef A, Çavdar S, Öner C, Sönmez Aİ, Şencan G, Telatar B, ve ark. Tıp Fakültesi Öğrencilerinde Empati Düzeyi ve Etkileyen Faktörler. VIII Ulusal Tıp Eğitimi Kongresi; İstanbul 2014. p. 35-6.

20. Brown T, Williams B, Boyle M, Molloy A, McKenna L, Molloy L, et al. Levels of empathy in undergraduate occupational therapy students: Occup Ther Int 2010; 17: 13541. [CrossRef]

21. McKenna L, Boyle M, Brown T, Williams B, Molloy A, Lewis $B$, et al. Levels of empathy in undergraduate midwifery students: An Australian cross-sectional study. Women Birth 2011; 24: 80-4. [CrossRef]

22. Hall M, Hanna L-A, Hanna A, McDevitt C. Empathy in UK pharmacy students: Assessing differences by gender, level in the 
degree programme, part-time employment and medical status. Pharmacy Education. 2015; 15: 241-7.

23. Williams B, Boyle M, Howard S. Empathy levels in undergraduate paramedic students: A three-year longitudinal study. Nurs Educ Pract 2016; 16: 86-90. [CrossRef]

24. Shariat SV, Habibi M. Empathy in Iranian medical students: Measurement model of the Jefferson scale of empathy. Med Teach 2013; 35: e913-e8. [CrossRef]

25. Park KH, Roh H, Suh DH, Hojat M. Empathy in Korean medical students: Findings from a nationwide survey. Med Teach 2015; 37: 943-8. [CrossRef]
26. Paro HB, Daud-Gallotti RM, Tibério IC, Pinto RM, Martins MA. Brazilian version of the Jefferson Scale of empathy: psychometric properties and factor analysis. BMC Med Educ 2012; 12: 1-7. [CrossRef]

27. Rahimi-Madiseh M, Tavakol M, Dennick R, Nasiri J. Empathy in Iranian medical students: A preliminary psychometric analysis and differences by gender and year of medical school. Med Teach 2010; 32: e471-e8. [CrossRef]

28. Kataoka HU, Koide N, Hojat M, Gonnella JS. Measurement and correlates of empathy among female Japanese physicians. BMC Med Educ 2012; 12: 1-6. [CrossRef] 